NAN HE, Ph.D. ${ }^{1}$

(Corresponding author)

E-mail: honny_he@hotmail.com

JITAO LI, Ph.D. Candidate ${ }^{1}$

E-mail: to_lijitao@djtu.edu.cn

YU WANG, Ph.D. ${ }^{1}$

E-mail: wangyudjtu@163.com

CAIWEN MA, Ph.D. ${ }^{1}$

E-mail: macaiwen@djtu.edu.cn

${ }^{1}$ Traffic \& Transportation School, Dalian Jiaotong University

Dalian 116028, China
Transport and Sustainable Development

Preliminary Communication

Submitted: 17 Aug. 2016

Accepted: 7 Apr. 2017

\title{
RAIL-INDUCED TRAFFIC IN CHINA
}

\begin{abstract}
The rapid development of China's railway has exerted an enormous influence on the intercity passenger transport structure in recent years. However, it has not satisfied the passengers' travel demand due to induced traffic. This paper is committed to solving such issue, with the aim of satisfying the current travel demand, and of anticipating the demand of the predicted traffic growth over the next 20 to 30 years. The paper has considered the increase in rail passenger kilometres caused by the growth of rail kilometres as rail-induced traffic. Based on the concept and former research of induced traffic, the panel data of 26 provinces and 3 municipalities of China between the year 2000 and 2014 were collected, and the elasticity models (including elasticity-based model, distributed lag model, high-speed rail (HSR) elasticity model and rail efficiency model) have been constructed. The results show the importance of model formation incorporation of rail-induced traffic. It is better to get the correct value in divided zones with different train frequencies or incorporation rail efficiency in cities or provinces. The lag time and rail types also need to be considered. In summary, the results analysis not only confirms the existence of rail-induced traffic, but also provides substantial recommendations to train operation planning.
\end{abstract}

\section{KEY WORDS}

train operation planning; rail-induced traffic; elasticity model; rail kilometres; rail passenger kilometres;

\section{INTRODUCTION}

Accurate traffic forecasts are central to proper appraisal of rail schemes, considering whether there are new railway constructions. The evaluation of the economic costs and benefits, and the appraisal of the safety and environmental impacts of the scheme are dependent on predictions of the amount and pattern of traffic using the new network compared with the one on the existing network. The scheme design is also determined by these forecasts. Under China's high-speed rail fast development, one question is: does improving the rail system introduce extra traffic, which would not otherwise be there without the improvements? Extra traffic may be caused, for example, by people, in response to improved rail conditions, making more or longer trips. Therefore, rail-induced traffic is necessary to the accurate prediction, which means the generation of new rail traffic that would not have occurred at all without the capacity improvement.

The traditional four-step model has been used both in road and rail transportation planning. Due to the travel demand difference between road and rail, road-induced traffic models have not been applied in rail transport. There are merely few studies on rail-induced traffic, owing to the frequency-based approach. People would make a choice following the schedule time rather than vehicles' free chosen at any time. Therefore, the relationship between rail kilometres and rail passenger kilometres is the necessary reason to make train timetable based on the traffic forecasting, especially induced traffic has effect on travel demand. Until now, rail demand forecasting models could be distinguished as aggregate and disaggregate. Aggregate models are used to forecast railway demand based on aggregate demand elasticity values to GRP variations, railway travel times, fuel costs, population and so on. These models have not incorporated the rail kilometres' influencing [1, 2]. Disaggregate models focus on the competition among multi-modes, showing the effect of mode changes [3-6]. These models have not considered the cooperated relationship among road, rail and air transport, underestimating rail kilometres influencing. Therefore, present model formations have neglected induced traffic, which should be further researched.

The aim of this paper is to find out rail-induced traffic, and then construct the elasticity models for quantification and analysis. Elasticity models come from aggregate model following the research ideology of road-induced traffic, on the assumption that rail frequency-based approach has not constrained passengers' free chosen at any time. The rest of this paper is structured as follows. Section 2 describes the concept definition of rail-induced traffic. Section 3 shows 
the data collection and analysis according to the influencing factors on people travel choices, based on the evidence of researches. Section 4 proposes some elasticity models and gets the elastic coefficients between rail kilometres and rail passenger kilometres, considering the population and GRP. Then these results are analysed in detail. The final section provides a summary of the research.

\section{RAIL-INDUCED TRAFFIC CONCEPT}

Rail-induced traffic means the additional demand due to the improvement of rail level of services. Rail improvement will have impact on peoples decision, such as trip generation (Whether or not to travel at all), trip distribution (Which destination is best for the purpose), trip scheduling (When is the best time to set out on the journey), mode choices (Which is the best mode of transport to use) and trip frequency (How often to repeat the journey within a given period). According to road-induced traffic studies, diverted demand and induced traffic are not separated in consideration. This means induced traffic is the generation of new vehicle traffic that would not have occurred at all without the capacity improvement, including time influencing. If after rail operation, you change other travel modes to rail, this is also induced traffic rather than diverted traffic. Following the ideology of road-induced traffic [7-12], the study on rail-induced traffic is mainly about the relationship between rail kilometres and rail passenger kilometres. The detail rail-induced traffic concept is in Figure 1, routinely used in this paper.

Figure 1 shows the generated process of rail-induced traffic. Railway construction will increase rail accessibility, which directly affects people's generalized travel cost. People would change travel choices such as trip frequency, destination or activity pattern, departure time etc. Considering over the long run, rail travel mode chosen will become one habit, indirectly due to modifications of travellers' lifestyle choices and land use. Therefore, rail construction will affect passengers' travel habit, such as change of route, change in time, change in origins or destination, switching modes, and increase in trip frequency. Both switching from other modes to rail and the increase in trip frequency are apparently rail-induced traffic. Only the increase of rail passenger kilometres is regarded as induced traffic, among changing of routes, changing in timing and changing origins or destinations.

\section{DATA COLLECTION AND ANALYSIS}

\subsection{Data collection}

According to the economic theory of supply and demand, value is the determinant of people choosing travel or not. The growth of rail kilometres will increase rail accessibility, which means the generalized travel costs will be reduced. GRP (Gross Regional Product) is the influencing factor that causes people get rich and reduces the relative costs. Population is also the influencing factor, whose growth would inevitably lead to increased traffic. Therefore, the factors that affect rail passenger kilometres include population, rail kilometres, and GRP.

Based on the influencing factors, the data are collected through the national statistical databases [13], including 26 provinces and 3 municipalities of China between 2000 and 2014. The main reason for excluding the Xizang Autonomous Region was no rail construction before 2007, and in the Hainan province it was the lack of data from 2004 to 2007. For each province and city, the data collection includes population, GRP, rail kilometres and rail passenger kilometres. Basic characteristics of the provinces and cities are shown in Table 1.

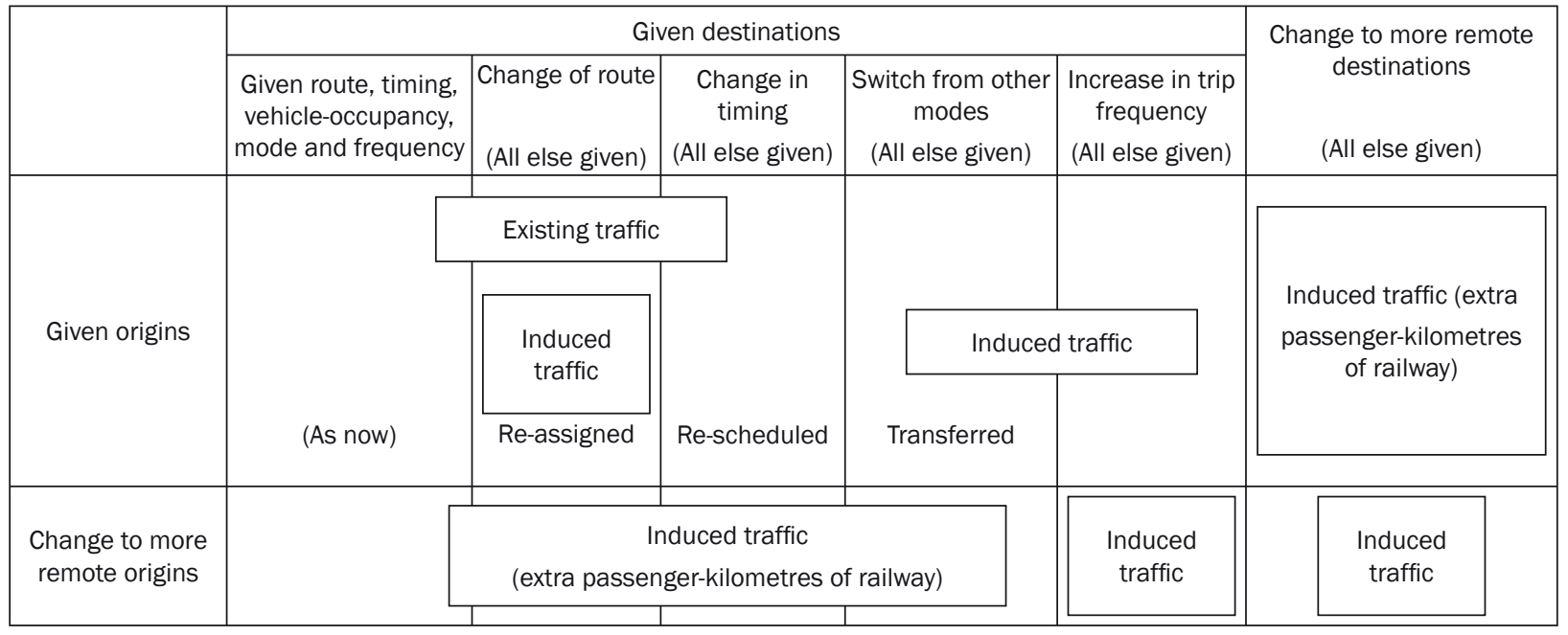

Figure 1 - Definitions of rail-induced traffic 
Table 1 - Average data in China

\begin{tabular}{|c|c|c|c|c|}
\hline Cities and provinces & $\begin{array}{l}\text { Average GRP } \\
\text { (Billion Yuan) }\end{array}$ & $\begin{array}{l}\text { Average population } \\
\text { (Million people) }\end{array}$ & $\begin{array}{c}\text { Average rail } \\
\text { kilometres }[\mathrm{Km}]\end{array}$ & $\begin{array}{c}\text { Average rail } \\
\text { passenger kilometres } \\
\text { [Billion passenger } \mathrm{Km}]\end{array}$ \\
\hline Beijing city & $1,065.358$ & 17.256 & $1,173.333$ & 9.034 \\
\hline Tianjin city & 686.115 & 11.827 & 773.333 & 11.254 \\
\hline Hebei province & $1,531.077$ & 69.894 & $4,973.333$ & 61.395 \\
\hline Shanxi province & 669.413 & 34.319 & $3,420.000$ & 13.379 \\
\hline $\begin{array}{l}\text { Inner Mongolia } \\
\text { Autonomous Region }\end{array}$ & 804.876 & 24.341 & $7,460.000$ & 13.497 \\
\hline Liaoning province & $1,377.348$ & 42.921 & $4,293.333$ & 44.330 \\
\hline Jilin province & 647.431 & 27.251 & $3,846.667$ & 18.062 \\
\hline Heilongjiang province & 805.694 & 38.233 & $5,706.667$ & 21.175 \\
\hline Shanghai city & $1,292.326$ & 20.487 & 360.000 & 5.362 \\
\hline Jiangsu province & $3,048.653$ & 76.799 & $1,746.667$ & 31.420 \\
\hline Zhejiang province & $2,049.172$ & 51.377 & $1,486.667$ & 28.561 \\
\hline Anhui province & 940.261 & 60.931 & $2,673.333$ & 36.982 \\
\hline Fujian province & $1,116.146$ & 36.108 & $1,813.333$ & 12.444 \\
\hline Jiangxi province & 709.499 & 43.642 & $2,640.000$ & 45.652 \\
\hline Shandong province & $2,899.892$ & 93.779 & $3,566.667$ & 36.647 \\
\hline Henan province & $1,695.046$ & 94.757 & $4,066.667$ & 63.791 \\
\hline Hubei province & $1,199.213$ & 57.181 & 2,893.333 & 38.483 \\
\hline Hunan province & $1,197.978$ & 65.460 & $3,253.333$ & 60.614 \\
\hline Guangdong province & $3,431.797$ & 97.017 & $2,406.667$ & 39.992 \\
\hline $\begin{array}{l}\text { Guangxi Zhuang } \\
\text { Autonomous Region }\end{array}$ & 712.801 & 47.557 & $3,000.000$ & 14.893 \\
\hline Chongqing city & 615.721 & 28.612 & 1,173.333 & 7.700 \\
\hline Sichuan province & $1,300.422$ & 81.398 & $3,133.333$ & 22.078 \\
\hline Guizhou province & 371.486 & 36.529 & $1,973.333$ & 16.090 \\
\hline Yunnan province & 581.728 & 45.004 & $2,373.333$ & 6.826 \\
\hline Shaanxi province & 751.568 & 37.083 & $3,420.000$ & 31.283 \\
\hline Gansu province & 319.514 & 25.512 & $2,473.333$ & 26.015 \\
\hline Qinghai province & 101.264 & 5.507 & $1,553.333$ & 3.251 \\
\hline $\begin{array}{l}\text { Ningxia Hui } \\
\text { Autonomous Region }\end{array}$ & 121.798 & 6.097 & 960.000 & 2.911 \\
\hline Xinjiang Uygur Auto & 423.108 & 20.774 & $3,453.333$ & 13.737 \\
\hline All & $32,466.705$ & $1,297.653$ & $82,066.664$ & 736.858 \\
\hline
\end{tabular}

Table 1 shows that the growth of average population and GRP will increase rail passenger kilometres in most cities or provinces. Rail kilometres present one special quality. The growth of rail kilometres will increase rail passenger kilometres in the same city or province. Meanwhile, more rail kilometres will not generate more rail passenger kilometres in different cities or provinces.

\subsection{Granger causality}

Granger causality could define the causality relationship between dependent variable and independent variable. According to the Granger test, both a backward and a forward lag exist in the regression. If the backward lag is statistically significant while the forward lag is not, then this indicates that the independent variable temporally precedes the dependent variable. If the significance is reversed, then the dependent variable precedes the independent variable. The relationship between rail kilometres and rail passenger kilometres is vital to express induced traffic. The results for the Granger test are presented in Table 2. The backward lag one year is statistically significant above the 95\% level. The forward lag is not statistically significant. So this result suggests that rail 
Table 2 - Results of the Granger test in China

\begin{tabular}{|l|c|c|c|c|c|c||}
\hline \hline $\begin{array}{c}\text { Independent } \\
\text { variables }\end{array}$ & $\begin{array}{c}\text { log(rail-kilometres) } \\
\text { backward lag one year }\end{array}$ & $\begin{array}{c}\log (\text { rail-kilometres) } \\
\text { forward lag one year }\end{array}$ & $\log (G R P)$ & $\log$ (population) & constant & $R^{2}$ \\
\hline Value & 0.368 & -0.020 & 0.325 & 0.419 & 2.089 & 0.895 \\
\hline$t$-statistic & 13.629 & -0.781 & 18.765 & 4.835 & 3.440 & \\
\hline
\end{tabular}

kilometre growth precedes the growth in rail passenger kilometres.

\subsection{Serial correlation and heteroscedasticity}

Serial correlation means the relative relationship among values of the same random variable at different time or space. Time series data often exhibit serial correlation at different periods. Heteroscedasticity means that regression interference variance does not remain constant in different observed data. In the amount of applied studies, the cross-section data and time-series data always appear heteroscedasticity. Based on the data collection, correlograms in Eviews show that some individual province and city residuals existing serial correlation and the White heteroscedasticity test implies the yearly heteroscedasticity (shown in Table 3) [14]. The method of period seemingly unrelated regressions (SUR) of generalized least squares

Table 3 - Serial correlation and heteroskedasticity test in cities and provinces

\begin{tabular}{|c|c|c|}
\hline Cities and provinces & $\begin{array}{l}\text { Breusch-Godfrey Lagrange Multiplier test } \\
\text { (Prob Chi-square serial correlation) }\end{array}$ & $\begin{array}{c}\text { White test } \\
\text { (Prob Chi-square heteroskedasticity) }\end{array}$ \\
\hline Beijing city & 0.413 & 0.900 \\
\hline Tianjin city & $0.093 * *$ & $0.162 *$ \\
\hline Hebei province & 0.491 & 0.659 \\
\hline Shanxi province & 0.388 & 0.692 \\
\hline Inner Mongolia Autonomous Region & 0.322 & 0.481 \\
\hline Liaoning province & $0.171 *$ & $0.038 * *$ \\
\hline Jilin province & 0.223 & 0.169 \\
\hline Heilongjiang province & 0.275 & 0.838 \\
\hline Shanghai city & $0.178 *$ & 0.406 \\
\hline Jiangsu province & 0.776 & 0.697 \\
\hline Zhejiang province & 0.759 & $0.080 * *$ \\
\hline Anhui province & 0.832 & 0.868 \\
\hline Fujian province & $0.145 *$ & 0.216 \\
\hline Jiangxi province & 0.466 & 0.899 \\
\hline Shandong province & 0.783 & $0.161 *$ \\
\hline Henan province & 0.843 & 0.806 \\
\hline Hubei province & $0.148 *$ & 0.427 \\
\hline Hunan province & 0.589 & 0.641 \\
\hline Guangdong province & $0.140 *$ & 0.203 \\
\hline Guangxi Zhuang Autonomous Region & $0.036 *$ & 0.345 \\
\hline Chongqing city & $0.014 * *$ & $0.157 *$ \\
\hline Sichuan province & 0.589 & 0.537 \\
\hline Guizhou province & $0.082 * *$ & 0.767 \\
\hline Yunnan province & 0.874 & 0.277 \\
\hline Shaanxi province & $0.099 * *$ & 0.386 \\
\hline Gansu province & $0.077 * *$ & 0.465 \\
\hline Qinghai province & 0.772 & 0.405 \\
\hline Ningxia Hui Autonomous Region & 0.729 & 0.314 \\
\hline Xinjiang Uygur Auto & 0.388 & 0.889 \\
\hline
\end{tabular}

Note: ** means rejection region is $10 \%$, * means rejection region is $20 \%$. 
and period SUR of coefficient covariance can eliminate those problems efficiently [15]. The above dummy models all use these methods to reach the results.

\section{ELASTICITY MODEL CONSTRUCTION AND RESULTS ANALYSIS}

Based on the collected influencing factors, elasticity model should be constructed. Induced traffic elasticity means the rate of change of rail passenger kilometres with respect to rail kilometres (Michael D. Meyer Eric J. Miller. 2001). Elasticity is thus a measure of the sensitivity to change in system conditions. From the economic view, the use of elasticity model has two advantages. First, the change of the unit measure will not affect the slope coefficient. So the units need not to be converted. Second, the log form of every variable can eliminate heteroscedasticity under normal circumstances. Above all, the elasticity model is the essential method to investigate in induced traffic [7-12]. A variety of statistical methods, discussed below, were estimated.

\subsection{Elasticity-based model construction and results analysis}

\subsubsection{Elasticity-based model}

Considering the impact factors of rail passenger kilometres, the basic model is set as:

$$
\begin{aligned}
\log \left(R P T_{i t}\right)= & c+\alpha_{i}+\tau_{t}+\sum_{k} \beta^{k} \log \left(X_{i t}^{k}\right)+ \\
& +\lambda \log \left(R K_{i t}\right)+\varepsilon_{i t}
\end{aligned}
$$

The parameters are defined as:

$R P T_{i t}$ - rail passenger kilometres in region $i$, for year $t$;

C - constant term;

$\alpha_{i} \quad$ - fixed effect for region $i$, to be estimated;

$\tau_{t} \quad$ - fixed effect for year $t$, to be estimated;

$\beta^{k} \quad$ - coefficients to be estimated for demographic and other parameters;

$X_{i t}^{k} \quad$ - value of demographic and other variables in region $i$ for year $t$;

$\lambda$ - coefficient to be estimated for rail kilometres parameter;

$R K_{i t}$ - proxy for cost of travel time (rail kilometres) in region $i$ for year $t$

$\varepsilon_{i t} \quad$ - random error term

The elasticity coefficient between rail kilometres and rail passenger kilometres is valued $\lambda$. This means that rail-kilometres increased by $1 \%$, rail passenger kilometres will grow $\lambda \%$. This model assumes that the elasticity coefficient of different regions at different time is the same. Similarly, the elasticity coefficient between other influencing factors and rail passenger kilometres is valued $\beta^{k}$.

\subsubsection{Results analysis}

Based on the model structure and data collection, Table 4 presents the results of estimating the elasticity-based model using software Eviews 6.0. Almost all the coefficients were estimated with a high degree of precision, obtaining plausible signs and magnitudes. These prove that the usefulness of the elasticity-based model can show the relationships among influencing factors in an accurate way. The high $R^{2}$ and $F$ value mean the accurate model formation. The Durbin-Watson statistic means residual serial correlation does not exist in the model.

Table 4 shows the results of the estimation using the elasticity-based model. All coefficient signs have the expected direction, suggesting that the hypothesis of rail-induced traffic cannot be rejected. The rail kilometres elasticity of rail passenger kilometres is 0.301 , meaning a $1 \%$ growth of rail kilometres will increase $0.301 \%$ rail passenger kilometres. Both population and GRP have significant impact on rail passenger kilometres. These show that when the population increases by $1 \%$, rail passenger kilometres will grow by $0.434 \%$; and a $1 \%$ growth of GRP will increase the rail passenger kilometres by $0.340 \%$. Comparing the population elasticity and GRP elasticity of rail-induced traffic with road-induced traffic in Zhao and He, the parameters value are similar. These reflect that rail transport is an essential part in China when people choose travel modes. The elasticities of rail kilometres, population and GRP have a small difference, which supports the importance of induced traffic consideration.

Due to various city and province characteristics, rail kilometre influences on rail passenger kilometres should be different. Take Inner Mongolia Autonomous Region for example, owning a large amount of railways will generate few rail passenger kilometres. In order to distinguish different relationship types between rail kilometres and rail passenger kilometres, China will be divided into four regions according to train frequency. The first zone is the region where train frequency is more than 300 times a day, including Beijing city, Shanghai city, Jiangsu province, Hubei province, and

Table 4 - Results of the elasticity-based model in China

\begin{tabular}{||l|c|c|c|c|c|c|c||}
\hline $\begin{array}{c}\text { Independent } \\
\text { variables }\end{array}$ & $\log$ (rail-kilometres) & $\log (\mathrm{GRP})$ & $\log ($ population) & constant & $R^{2}$ & $F$-statistic & DW-statistic \\
\hline \hline Value & 0.301 & 0.340 & 0.434 & 1.947 & \multirow{2}{*}{0.812} & 619.650 & 1.848 \\
\hline t-statistic & 12.502 & 24.437 & 5.618 & 3.569 & & \\
\hline
\end{tabular}


Guangdong province. The second zone is the region where train frequency is more than 200 times a day, including Tianjin city, Hebei province, Liaoning province, Zhejiang province, Shandong province, Henan province, and Hunan province. These two zones are with high economic development or large population density. The third zone is the region where train frequency is more than 100 times a day, including Jilin province, Heilongjiang province, Anhui province, Fujian province, Jiangxi province, Sichuan province, and Shanxi province. The fourth zone is the region where train frequency is less than 100 times a day, including Shaanxi province, Inner Mongolia Autonomous Region, Guangxi Zhuang Autonomous Region, Chongqing city, Guizhou province, Yunnan province, Gansu province, Qinghai province, Ningxia Hui Autonomous Region, and Xinjiang Uygur Auto. These two zones are with low economic development or small population density. Based on elasticity-based model formation and data collection, the results in the divided zones are shown in Table 5.

Table 5 shows that various divided zones can be efficiently described by elasticity-based model, using high $R^{2}$ and F-statistics. The rail kilometres elasticity of rail passenger kilometres in different divided zones is larger than that in China. Meanwhile, the GRP elasticity of rail passenger kilometres in different divided zones is smaller than that in China. These reflect that the influencing of rail kilometres has been underestimated in China, and the effect of GRP has been overestimated due to various social economy, population, and environment in cities or provinces. Huge differences among the divided zones are the arrival or departure frequency of train. The detail results will be analysed from the following three points.

In the first zone, the rail kilometres elasticity of rail passenger kilometres is 0.609 , meaning a $1 \%$ growth of rail kilometres will increase rail passenger kilometres by $0.609 \%$. These show that in case of rail construction, people will be attracted to rail transport, reflecting the importance of induced traffic. The GRP elasticity of rail passenger kilometres is 0.155 , reflecting that people can totally afford ticket price at present. The population elasticity of rail passenger kilometres is 0.531; larger than in other divided zones and China. This means that more than half of people would like to choose rail transport for long-distance travel. Therefore, the highest arrival or departure frequency of train aims to meet passengers' travel demand. We suggest railway station reconstruction in the first zone to afford the increasing train frequency.

In the second zone, the rail kilometres elasticity of rail passenger kilometres is 0.678 , the largest in other divided zones. Both GRP (0.166) and population (0.140) elasticities of rail passenger kilometres are significantly positive; the value is small. These reflect that passengers' travel demand in rail transport may have been restricted due to low train frequency. Meanwhile, GRP elasticity of rail passenger kilometres shows passengers have weak reaction to ticket prices. Railway construction will increase train frequency to meet the passengers' travel demand. However, the increased ticket prices will not cut down the passengers' travel demand. Therefore, the growth of arrival or departure frequency of train in the second zone is suggested.

The results in both the third and the fourth zone have similar values. The GRP elasticity of rail passenger kilometres is 0.225 in the third zone, 0.273 in the fourth zone, showing the economic development may have effect on passengers' travel demand, compared with the first and the second zone. The rail kilometres elasticity of rail passenger kilometres is 0.390 in the third zone, and 0.409 in the fourth zone. And the population elasticity of rail passenger kilometres is 0.361 in the third zone, and 0.330 in the fourth zone, showing that passengers travel modes are chosen at free condition compared with the first and the second zone. Therefore, whether railway improvement and construction should be undertaken or not should be decided on the basis of a detailed analysis of individual city or province. Take Jilin province and Inner Mongolia Autonomous Region for example, the current railway construction is available to Jilin province due to

Table 5 - Results of the elasticity-based model in divided zones

\begin{tabular}{|c|c|c|c|c|}
\hline Independent variables & First zone & Second zone & Third zone & Fourth zone \\
\hline log(rail-kilometres) & $\begin{array}{r}0.609 \\
(33.011)\end{array}$ & $\begin{array}{c}0.678 \\
(49.129)\end{array}$ & $\begin{array}{c}0.390 \\
(19.303)\end{array}$ & $\begin{array}{c}0.409 \\
(38.953)\end{array}$ \\
\hline $\log (G R P)$ & $\begin{array}{c}0.155 \\
(6.286)\end{array}$ & $\begin{array}{c}0.166 \\
(10.820)\end{array}$ & $\begin{array}{c}0.225 \\
(12.978)\end{array}$ & $\begin{array}{c}0.273 \\
(27.313)\end{array}$ \\
\hline $\log ($ population) & $\begin{array}{c}0.531 \\
(20.107)\end{array}$ & $\begin{array}{c}0.140 \\
(9.899)\end{array}$ & $\begin{array}{c}0.361 \\
(24.676)\end{array}$ & $\begin{array}{c}0.330 \\
(34.310)\end{array}$ \\
\hline constant & $\begin{array}{c}2.404 \\
(11.917)\end{array}$ & $\begin{array}{c}5.158 \\
(38.145)\end{array}$ & $\begin{array}{c}3.596 \\
(24.029)\end{array}$ & $\begin{array}{c}3.023 \\
(48.682)\end{array}$ \\
\hline$R^{2}$ & 0.982 & 0.996 & 0.962 & 0.996 \\
\hline F-statistic & $1,265.843$ & $8,576.705$ & 845.890 & $12,024.860$ \\
\hline
\end{tabular}


population and economy, and new railway construction is necessary for Inner Mongolia Autonomous Region due to geography.

\subsection{Distributed lag model construction and results analysis}

\subsubsection{Distributed lag model}

The growth of rail kilometres will increase rail passenger kilometres, which is called induced traffic in this paper. All induced traffic should not be generated in the first year. Rail development can also have a profound and long-term effect not only on the fabric of the nation, but also on the regional and local land-use patterns, the environment and the way in which people conduct their business and personal lives. Therefore, rail kilometres influencing rail passenger kilometres is consistent with the growth curve model. This means that the increase of rail passenger kilometres is not a transient response, but a long response after new rail. In summary, the lag model is important. It considers the time influence based on the basic model. The model is set as:

$$
\begin{aligned}
\log \left(R P T_{i t}\right)= & c+\sum_{k} \beta^{k} \log \left(X_{i t}^{k}\right)+ \\
& +\sum_{l} \lambda^{\prime} \log \left(R K_{i(t-l)}\right)+\varepsilon_{i t}
\end{aligned}
$$

The parameters are defined as:

$\lambda^{\prime} \quad$ - undetermined coefficient;

$R K_{i(t-l)}$ - rail kilometres in region $i$ for year $t-l$.

The lag model considers not only the demographic and economic factors, but also the time lag effect. This reflects the response of new or improved road, so as rail kilometres in region $i$ of year $t$ are related with rail passenger kilometres of year $t-I$. Elasticities of rail kilometres with respect to rail passenger kilometres correspond to the coefficient on the rail-kilometres variable $\sum_{l=0}^{L} \lambda^{\prime}$. This model assumes that the elasticity coefficient of different regions at the same time period is the same.

\subsubsection{Results analysis}

Based on the model structure and data collection, Table 6 presents the results of estimating the lag model using software Eviews 6.0. Using cross correlogram could get the 6 -lag year. These results in Table 6 show that almost all the coefficients were estimated with a high degree of precision, obtaining plausible signs and magnitudes. These prove that the usefulness of lag model can show the time effect in an accurate way. High $R^{2}$ and $F$ value means the accurate model formation. Durbin-Watson statistics means that the residual serial correlation does not exist in the model.

These results in Table 6 suggest that the time effect needs to be considered. The lag rail kilometres elasticity with respect to rail passenger kilometres is significantly positive, increasing with time. These elasticity values reflect people's reaction to rail improvement and cultivated travel mode choices habit. The rail kilometres elasticity of rail passenger kilometres is 0.056 in the short term and 0.435 in the long term. These mean that the new or improved railway will increase rail passenger kilometres less in the first year, whereas big growth is expected in the later years. The rail kilometres' time effect on rail passenger kilometres reflect cumulated increase. Both GRP and population are also significant to rail passenger kilometres, whose value is similar to elasticity-based model.

\subsection{HSR elasticity model construction and results analysis}

\subsubsection{HSR elasticity model}

The first HSR in China is the Qinhuangdao-Shenyang HSR, which has been in operation since 2003. After that, different provinces or cities started to build HSRs. In 2015, China's HSR operating mileage of $19,000 \mathrm{~km}$ was the highest in the world. The fast development of HSR has affected the passengers travel pattern, travel frequency, and travel distance, etc. Therefore, HSR should be considered in the separated way from the entyre rail network. The conventional rail kilometres and HSR kilometres are included in the HSR

Table 6 - Results of the lag model in China

\begin{tabular}{||l|c|c|c|c|c||}
\hline \multicolumn{1}{|c|}{ Independent variables } & $\log \left(R K_{i t}\right)$ & $\log \left(R K_{i(t-1)}\right)$ & $\log \left(R K_{i(t-2)}\right)$ & $\log \left(R K_{i(t-3)}\right)$ & $\log \left(R K_{i(t-4)}\right)$ \\
\hline \hline Value & 0.056 & 0.061 & 0.066 & 0.070 & 0.075 \\
\hline \hline -statistic & 2.377 & 3.377 & 5.074 & 6.503 & 5.660 \\
\hline \hline Variables & $\log \left(R K_{i(t-5)}\right)$ & $\log \left(R K_{i(t-6)}\right)$ & $\log (G R P)$ & $\log ($ population $)$ & constant \\
\hline$t$-statistic & 0.079 & 0.084 & 0.259 & 0.450 & 2.180 \\
\hline \multicolumn{2}{|r|r|r|}{ F-statistic: 133.114} & 4.734 & 3.340 \\
\hline
\end{tabular}

Note: $R K$ means rail kilometres 
elasticity model to show individual influences of different rail types. However, some provinces have not constructed HSR until 2014, such as Inner Mongolia Autonomous Region, Guizhou province, Yunnan province, Xizang Autonomous Region, Shaanxi province, Gansu province, Qinghai province, Ningxia Hui Autonomous Region, Xinjiang Uygur Auto and Hainan province. In summary, the HSR elasticity model is constructed to consider rail type influences. The model is set as:

$$
\begin{aligned}
\log \left(R P T_{i t}\right)= & c+\alpha_{i}+\tau_{t}+\sum_{k} \beta^{k} \log \left(X_{i t}^{k}\right)+ \\
& +\delta \log \left(N K_{i t}\right)+\gamma \log \left(H K_{i t}\right)+\varepsilon_{i t}
\end{aligned}
$$

The parameters are defined as:

$N K_{i t}$ - conventional rail kilometres in region i for year $t$; $H K_{i t}-$ HSR kilometres in region $i$ for year $t$;

$\delta$ - coefficient to be estimated for conventional rai parameter;

$\gamma \quad$ - coefficient to be estimated for HSR parameter.

The HSR elasticity model shows the interrelationships between rail passenger kilometres on various rail types to improve model estimation using contemporaneous correlation between error terms. This reflects various responses of the new or improved rail. Elasticity of conventional rail kilometres with respect to rail passenger kilometres is $\delta$. And the elasticity of HSR kilometres with respect to rail passenger kilometres is $\gamma$. This model assumes that a given amount of rail passenger kilometres on conventional rail will not affect the amount of rail passenger kilometres on HSR. The reverse is also reasonable.

\subsubsection{Results analysis}

Based on the model structure and data collection, Table 7 presents the results of estimating the HSR elasticity model using software Eviews 6.0. These results in Table 7 show that all the coefficients were estimated with a high degree of precision, obtaining plausible signs and magnitudes. These prove that the usefulness of HSR elasticity model can show the influences of rail types. High $R^{2}$ and $F$ value means the accurate model formation. Durbin-Watson statistics means residual serial correlation does not exist in the model.

These results shown in Table 7 mean that the conventional railway elasticity to rail passenger kilometres (0.255) is nearly ten times larger than HSR elasticity to rail passenger kilometres (0.026). The huge elasticity gap is opposite to our basic thinking. This is due to three reasons. In the first place, HSR kilometres grow from null to 13,357 kilometres. The basic conventional rail is nearly 100,000 kilometres and the unit of rail passenger kilometres is billion. So, travel distance of HSR is shorter than the normal speed rail. It is easy to make HSR kilometres grow 1\%, but hard to increase the conventional rail by $0.1 \%$. In the second place, HSR construction has not formed the national network. Many provinces are constructing or planning to construct HSR. So, many zeroes in the model calculation will cause small coefficient using least squares method. In the third place, people should have response time to travel mode changes, due to less travel time and higher ticket prices with HSR. Therefore, HSR will cause huge effect on rail passenger kilometres, which should be considered. Both GRP and population are significant to rail passenger kilometres. The elasticity value of GRP and population in HSR elasticity model is similar with that in the elasticity-based model, which shows stable influencing.

\subsection{Rail efficiency model construction and results analysis}

\subsubsection{Rail efficiency model}

Since 2006, all cities and provinces have constructed railways. Due to rail transportation characteristic, only two directed ways between two cities should meet the peoples' travel demand. People should choose rail modes based on the train timetable. In order to satisfy the peoples' travel demand, railways should also be constructed in the rural region, in spite of fewer passengers. Therefore, the length of railway is decided by geographical conditions. Some cities or provinces own a large amount of railways, such as Inner Mongolia Autonomous Region, Hebei province, Shandong province, Xinjiang Uygur Auto and so on. On the other hand, some cities or provinces own a little amount of railways, such as, Shanghai city, Beijing city, and Tianjin city. These lead to low rail passenger kilometres in some cities that have long railways. Meanwhile, some cities that have short railways will generate high rail passenger kilometres. Therefore, the rail efficiency should reflect the real rail kilometres' influences on rail passenger kilometres in various regions. The specification for the rail efficiency model is set as:

Table 7 - Results of the HSR elasticity model in China

\begin{tabular}{||l|c|c|c|c|c|}
\hline \multicolumn{1}{|c|}{ Independent variables } & \begin{tabular}{c}
$\log \left(\begin{array}{c}\text { conventional } \\
\text { railway) }\end{array}\right.$ \\
\hline \hline Value
\end{tabular}$\quad 0.255$ & 0.026 & 0.332 & 0.485 & constant \\
\hline t-statistic & 9.216 & 8.217 & 17.744 & 5.590 & 2.873 \\
\hline \multicolumn{2}{|r|}{} & \multicolumn{2}{|c|}{ F-statistic: 271.778} & DW-statistic: 1.864 \\
\hline
\end{tabular}


Table 8 - Results of the efficiency model in China

\begin{tabular}{||l|c|c|c|c|c|c|c||}
\hline $\begin{array}{c}\text { Independent } \\
\text { variables }\end{array}$ & $\log ($ rail-kilometres) & $\log (G R P)$ & $\log ($ population) & constant & $R^{2}$ & $F$-statistic & DW-statistic \\
\hline \hline Value & 0.399 & -0.279 & 0.756 & 6.879 & \multirow{2}{*}{0.763} & 57.977 & 1.932 \\
\hline$t$-statistic & 5.369 & -2.695 & 5.972 & 6.444 & & \\
\hline
\end{tabular}

$$
\begin{aligned}
\log \left(R P T_{i t}\right)= & c+\alpha_{i}+\tau_{t}+\sum_{k} \beta^{k} \log \left(X_{i t}^{k}\right)+ \\
& +\lambda \log \left(\mu R K_{i t}\right)+\varepsilon_{i t}
\end{aligned}
$$

The parameter is defined as:

$\mu$ - the railway efficiency ratio.

Railway efficiency ratio $\mu$ is defined as individual city or province rail passenger kilometres per rail kilometres as a percentage of Beijing city rail passenger kilometres per rail kilometres. The elasticity coefficient between efficient rail kilometres and rail passenger kilometres is valued $\lambda$. This means that efficient rail kilometres increased by $1 \%$, and rail passenger kilometres will grow $\lambda \%$. This model assumes that the elasticity coefficient of different regions at different time is the same.

\subsubsection{Results analysis}

Based on the model structure and data collection, Table 8 presents the results of estimating the rail efficiency model using software Eviews 6.0. These results in Table 8 show that all the coefficients were estimated with a high degree of precision, obtaining plausible signs and magnitudes. High $R^{2}$ and $F$ value mean accurate model formation. Durbin-Watson statistics means residual serial correlation does not exist in the model. Due to little data collection in train timetable, only using 28 provinces and 3 municipalities of China in the year 2011 and 2012 the simulation results were obtained. The railway efficiency ratio is the percentage of passenger trains in other cities taking Beijing city in 2011.

Table 8 shows the results of the estimation using the rail efficiency model, suggesting that the $1 \%$ growth of rail kilometres will increase rail passenger kilometres by $0.399 \%$, larger than elasticity-based model. These show the necessity of efficiency ratio. Compared with elasticity-based model in Table 4, one special difference is that GRP elasticity of rail passenger kilometres is significantly negative, which is contradictory to people's basic thinking. We think it is because GRP development also makes people choose air transport. Due to HSR construction, air transport has to decrease air ticket price to compete with HSR. Therefore, passengers tend to choose HSR for short distances and air transport for long distances. Population has significant impact on rail passenger kilometres, showing the population increased by $1 \%$, rail passenger kilometres will grow by $0.756 \%$. The population elasticity is nearly
Table 9 - Errors between actual and predicted values in China

\begin{tabular}{||l|c||}
\hline \multicolumn{1}{|c|}{ City or province } & Error \\
\hline \hline Beijing city & 0.014 \\
\hline Tianjin city & -0.015 \\
\hline Hebei province & -0.017 \\
\hline Inner Mongolia Autonomous Region & 0.021 \\
\hline Shanxi province & 0.017 \\
\hline Liaoning province & -0.015 \\
\hline Jilin province & 0.0001 \\
\hline Heilongjiang province & 0.009 \\
\hline Shanghai city & 0.028 \\
\hline Jiangsu province & 0.009 \\
\hline Zhejiang province & -0.001 \\
\hline Anhui province & -0.013 \\
\hline Fujian province & 0.023 \\
\hline Jiangxi province & -0.032 \\
\hline Shandong province & 0.014 \\
\hline Henan province & 0.015 \\
\hline Hubei province & -0.011 \\
\hline Hunan province & -0.027 \\
\hline Guangdong province & 0.008 \\
\hline Guangxi Zhuang Autonomous Region & 0.017 \\
\hline Chongqing city & 0.026 \\
\hline Sichuan province & 0.020 \\
\hline Guizhou province & -0.007 \\
\hline Yunnan province & 0.048 \\
\hline Shanxi province & -0.017 \\
\hline Gansu province & -0.030 \\
\hline Qinghai province & 0.010 \\
\hline Ningxia Hui Autonomous Region & 0.009 \\
\hline Xinjiang Uygur Auto & 0.0005 \\
\hline
\end{tabular}

1.75 times as elasticity-based, reflecting passengers would like to travel by train after 2010 .

\subsection{Errors analysis}

In order to show whether the model could predict rail demand, errors between actual and predicted values are shown in Table 9 in China on the basis of elasticity-based model. The results show that high precision (above 95\%) for prediction could guarantee travel demand model construction incorporation induced traffic. The error values appear both positive and negative, meaning the forecasting model could better predict travel demand. The differences in error 
values could show cities or provinces have different qualities, meaning that divided zones consideration are valuable to research.

\section{CONCLUSION}

Elasticity-based model, distributed lag model, HSR elasticity model and rail efficiency model are constructed to confirm the existence of induced traffic. So, it is necessary to consider the rail-induced traffic in China in the future. Time effect, divided zones, rail efficiency and HSR should be paid more attention to research. Based on the data collection of 26 provinces and 3 municipalities of China between the year 2000 and 2014, the rail kilometres' elastic coefficients to rail passenger kilometres turn out to be $0.026-0.678$. And the population also increases rail passenger kilometres. HSR elasticity to rail passenger kilometres is 0.026 , showing HSR kilometres growth of $1 \%$, and passenger-kilometres of railway increase $0.026 \%$. HSR increasing construction would generate considerable induced traffic under fast development of rail. In summary, different elasticity models can be suitable to various research aims. The forecasting will support the reasonable rail operational planning, which is suitable to passenger transportation planning.

\section{ACKNOWLEDGEMENT}

This research is supported by the Doctoral Research Foundation of Liaoning Province (No. 201601257). All possible errors in the paper are only with the authors, who are solely responsible for the facts and the accuracy of the data presented here.

何南, 博士, 讲师, 单位: 中国大连交通大学交通运输 工程学院

李季涛, 硕士, 副教授, 单位: 中国大连交通大学交通 运输工程学院

王宇, 博士, 讲师, 单位: 中国大连交通大学交通运输 工程学院

马彩雯, 博士, 教授, 单位: 中国大连交通大学交通运 输工程学院

\section{中国铁路诱增交通量}

\section{摘要}

近年来, 中国铁路的快速发展对城际客运运输结构 产生了巨大影响。然而由于诱增交通量的存在, 迅 猛增长的铁路里程并没有满足人们日益增长的需 求。铁路诱增交通量是铁路里程增长所导致铁路客 运周转量的增加。为了解决上述问题, 本文致力于 构建需求预测模型, 以实现当前交通需求的准确测 算，并可以有效预测考虑潜在需求的未来 20 年或 30 年的交通量。基于诱增交通量的定义和相关研究情 况，应用中国26个省市和 3 个自治区2000年-2014年 面板数据收集, 构建弹性系数模型, 其中包括基本 模型、分布滞后模型、高速铁路弹性系数模型和铁 路效用模型。结果表明了考虑铁路诱增交通量模型
构建的重要性。在省市中, 依据列车频率确定分区 或者考虑铁路效用将获得准确预测值。延迟时间和 铁路类型也需要考虑。总之, 结果分析不仅证明了 铁路诱增交通量的存在, 更为今后的铁路列车运行 计划提供实质建议。

关键词

列车运行计划; 铁路诱增交通量; 弹性系数模型; 铁路营业里程; 铁路客运周转量;

\section{REFERENCES}

[1] Wardman M. Demand for rail travel and the effects of external factors. Transportation Research Part E: Logistics \& Transportation Review. 2006;42(3): 129-148.

[2] Cascetta E, Ben-Akiva M, Coppola P, et al. High Speed Rail Demand Forecasting in a Competitive Market: the Italian Case Study. World Conference on Transportation Research WCTR 2010.

[3] Hsu Cl, Chung WM. A model for market share distribution between high-speed and conventional rail services in a transportation corridor. Annals of Regional Science. 1997;31(2): 121-153.

[4] Fröidh O. Perspectives for a future high-speed train in the Swedish domestic travel market. Journal of Transport Geography. 2008;16(4): 268-277.

[5] Cascetta E, Coppola P. High Speed Rail (HSR) Induced Demand Models. Procedia - Social and Behavioral Sciences. 2014;111: 147-156.

[6] Cascetta E, Coppola P. Assessment of schedule-based and frequency-based assignment models for strategic and operational planning of high-speed rail services. Transportation Research Part A: Policy \& Practice. 2015;84: 93-108.

[7] Fulton LM, Noland RB, Meszler DJ, et al. A statistical analysis of induced travel effects in the US mid-Atlantic region. Journal of Transportation and Statistics. 2000;3(1): 1-14.

[8] Hansen M, Gillen D, Dobbins A, et al. The Air Quality Impacts of Urban Highway Capacity Expansion: Traffic Generation and Land Use Change. University of California Transportation Center Working Papers; 1993.

[9] González RM, Marrero GA. Induced road traffic in Spanish regions: A dynamic panel data model. Transportation Research Part A: Policy \& Practice. 2012;46(3): 435-445.

[10] He N, Zhao S. Induced Traffic in China: Elasticity Models with Panel Data. Journal of Urban Planning \& Development. 2014;141(4): 04014046.

[11] Hymel KM, Small KA, Dender KV. Induced demand and rebound effects in road transport. Transportation Research Part B: Methodological. 2010;44(10): 1220-1241.

[12] Noland RB. Relationships between highway capacity and induced vehicle travel. Transportation. Research Part A: Policy and Practice. 2001;35(1):47-72.

[13] National Bureau of Statistics of China. 2000-2014. Available from: http://www.stats.gov.cn/

[14] White H. A Heteroskedasticity-Consistent Covariance Matrix and a Direct Test for Heteroskedasticity. Econometrica. 1980;48(4): 817-838.

[15] Bai ZL. The Unit Root Test in the panel data with longitudinal time series. Econometric Analysis of Panel Data. Tianjin: Nankai University Press; 2008. 